\title{
A preliminary evaluation of the Confident Kids Program - a stand alone component of the Exploring Together Program
}

\author{
Margot Trinder, Michelle Soltys and Susie Burke \\ Exploring Together, Carlton, Victoria, Australia
}

\begin{abstract}
This study was designed to evaluate the effectiveness of the Confident Kids Program, as a separate component of the multi-group Exploring Together Program (ETP). Confident Kids aims to reduce children's behavioural and emotional difficulties through a group program for primary school children that meets once weekly for 10 weeks. This report presents an analysis of pre-post data collected from 39 parents whose children attended the Confident Kids programs and 48 teachers in the state of Victoria. Following the program, significant improvements were noted in parent reports of children's internalising and externalising difficulties, levels of parenting satisfaction and parenting styles. Teachers also reported a significant improvement in children's internalising behaviour from pre- to post-program. The benefits of offering both multi-group and single component interventions in school and community settings are also discussed.
\end{abstract}

\section{Keywords}

children, teachers, parents, parenting, emotional problems, behavioural problems, evaluation, program evaluation

\section{Introduction}

Mental health problems are growing at an alarming rate with predictions of a 50 percent increase in the next decade compared with other health related problems (DeAngelis, 2004). Approximately one in five children experience mental health issues (DeAngelis, 2004; Maddern, Franey, McLaughlin \& Cox, 2004). Amongst primary school aged children (4-12 years) in Australia, 15 percent of boys and 14 percent of girls are reported to have clinically significant behavioural or emotional problems (Sawyer, Arney, Baghurst et al., 2001). Early identification of problems and effective interventions for children are crucial in reducing the rates of mental health problems in children.

Behavioural and emotional problems in primary school aged children can cause significant difficulties in children's healthy development.
For many children, they are also predictive of longer-term antisocial behaviours and mental health problems (Kazdin, 1995; Webster-Stratton \& Reid, 2003; Wren, Scholle, Heo \& Comer, 2003). Some children show symptoms that are consistent with diagnoses of Anxiety, Depression, Oppositional Defiant Disorder (ODD), Attention-Deficit Disorder (ADHD), and Conduct Disorder (CD) (American Psychiatric Association, 1994). As well as causing significant distress for children and families during their childhood, children with emotional and behavioural problems face an increased risk of low self-esteem, relationship problems with peers and family members, academic difficulties, early school leaving, adolescent homelessness, the development of substance abuse issues and criminality (Scott, Knapp, Henderson \& Maughan, 2001; Wren et al., 2003).
Contact:

Citation:

Published by:
Margot Trinder, Exploring Together Coordinator, Exploring Together, Carlton, Victoria Australia info@exploringtogether.com.au

Trinder, M., Soltys, M., \& Burke, S. (2008). A preliminary evaluation of the Confident Kids Program - a stand alone component of the Exploring Together Program. Australian e-Journal for the Advancement of Mental Health, 7(1), www.auseinet.com/journal/vol7iss1/trinder.pdf

Australian Network for Promotion, Prevention and Early Intervention for Mental Health (Auseinet) www.auseinet.com/journal

Received 18 September 2007; Revised 11 January 2008; Accepted 11 January 2008 
In order to address the current impacts on children's lives, as well as prevent long-term antisocial behaviours and mental health problems in adolescence and adulthood, early identification and effective treatment of childhood behavioural and emotional problems is crucial. Research has shown that the most effective interventions include parent training programs (Brestan \& Eyberg, 1998; Sanders, Ralph, Thompson et al., 2007; Taylor \& Biglan, 1998; Webster-Stratton \& Hammond, 1997), children's social problem solving and emotion management training (Kazdin, Esveldt-Dawson, French \& Unis, 1987; Shure, 1993; Spivack \& Shure, 1989), parent-child interaction therapy (Eyeberg, Boggs \& Algina, 1995) and a combination of these components (Hemphill \& Littlefield, 2001; Webster-Stratton \& Reid, 2003).

An effective intervention that combines parent behaviour management training, children's social problem solving and emotion management training and parent-child interactive therapy is the Exploring Together Program (ETP) (Hemphill \& Littlefield, 2001). Small groups of six to eight primary school aged children and their primary caregivers attend the ETP for 13/4 hours per week for 10 weeks. Separate, concurrent groups are held simultaneously for parents/carers and children (lasting 1 hour) each week, immediately followed by a combined parent-child group (lasting 45 minutes). Throughout the program, additional meetings are held on two occasions for attending parents and their partners or support people. Group leaders also meet twice with children's teachers, once near the start and again near the end of the program.

ETP was designed to be conducted as a shortterm intervention program for primary school aged children (6 to 12 years old). It has also been adapted for secondary school students (12 to 16 year olds) and for preschool aged children (3 to 6 year olds). Since the early 1990s, Exploring Together Programs for primary school students have been implemented in suburban and regional areas of Australia in a large variety of schools and community agencies, with the majority of programs being conducted by teachers, social workers and psychologists trained in the program. Studies have revealed the program's continuing effectiveness and efficacy (Hemphill,
1996; Hemphill \& Littlefield, 2001; Littlefield, Burke, Trinder et al., 2000).

ETP has always recognised that schools are an ideal setting to reach many families and their children in need of intervention for childhood behavioural and emotional problems. Enabling families to access suitable programs in a school setting helps address the growing tide of mental health concerns, and several studies corroborate the view that schools are an appropriate setting to provide evidence-based programs to children and adolescents (Maddern et al., 2004; Neil \& Christensen 2007; Weist, Lever \& Stephan, 2004). This view is also strongly supported by the Council of Australian Goverments (COAG, 2006). Benefits of school based interventions include the children's and families' familiarity with the setting; ease of access; reduction in stigma; and the fostering of collaborative links between schools and community agencies.

Despite these many benefits, ongoing consultations by the ETP team with trained leaders working in these settings identified a number of common concerns. The main ones were 1) the difficulty in resourcing a program that required four leaders, 2) the desire to offer interventions to students whose parents were not able to participate in a weekly program, 3) the need to conduct the programs during the day to accommodate primary school aged children, thus excluding parents employed during the day from attending the program, and 4) time restrictions for each individual group because they were being led simultaneously and concurrently with other components of the program that had different time requirements. Program leaders continually asked about the effectiveness of conducting the components of the ETP separately. While initially resisting these requests due to a strong commitment to a multifaceted approach - particularly the parenting component - the ETP team eventually agreed to respond to these requests by developing two components of the program to be used as stand-alone interventions. This resulted in the Confident Kids Program (for children) and the Together Parenting Program (for parents). The Confident Kids Program only requires two staff, can accommodate more students (up to 10) and is available to students whose parents are unable to attend a concurrent group during the day. The Together Parenting Program also 
offers flexible options and is described by Burke, Soltys and Trinder (2008) in this issue.

This pilot study aimed to determine whether Confident Kids is effective on its own to address children's behavioural and emotional difficulties. While offering an intervention predominantly to children would be expected to have a positive impact on the participating children, the question of whether changes in children's behaviour (in conjunction with two brief parent information meetings) would have any impact on parenting satisfaction and practices was also of interest. This pilot trial therefore set out to investigate whether participation in the Confident Kids Program decreases children's behavioural and emotional difficulties whilst also improving parenting satisfaction and parenting practices.

\section{Confident Kids Program}

Confident Kids is a 10-week group program for primary school aged children (6 to 12 years of age). The program is targeted at children exhibiting the following types of problem behaviours: those who engage in impulsive, aggressive or bullying behaviour, those who are withdrawn, anxious, or depressed, and/or those who have problematic peer relationships. Confident Kids focuses on developing children's social skills and reducing their problematic behaviour. Each session lasts for $1 \frac{1}{2} 2$ hours. Two meetings are held for parents, and group leaders also meet with children's teachers on two occasions. The program can be conducted in schools or community agencies with two leaders. Professionals with a background in psychology, social work, teaching or counselling who participate in a one-day training workshop, or who have previously trained in ETP, are able to run Confident Kids.

The aims of the Confident Kids Program are to reduce children's aggressive and/or withdrawn behaviours whilst improving peer interactions. This is done through activities such as games, stories and role-play. The content of the activities focus on teaching the children a range of skills incrementally over the course of the 10week program. The topics covered during the program include conversation skills, recognising feelings in oneself and others, anger/anxiety management, perspective taking, developing prosocial skills like sharing and turn-taking, problem solving, assertion skills, decision making and social perception. The program incorporates behavioural and cognitive behavioural techniques, but also has a strong emphasis on group process. Whilst providing a safe environment for the children, group leaders also focus on providing challenges to the children in order to better observe and address the issues for which each child has been referred. For example, during an activity involving drawing and cutting, the leaders will intentionally not provide enough scissors or pencils. When faced with this oft encountered situation of having to share limited resources, the externalising children generally demonstrate how they use power and force to get what they want, while the more internalising children tend to withdraw and let the more powerful children have the resources. By recreating real-life situations that these children often struggle with, the leaders are better able to directly address the respective behaviours these situations elicit and then help the children to learn more effective ways of managing these issues. This process also provides continuing opportunities for children to give and receive direct feedback from their peers and leaders about the impact of particular behaviours on others.

\section{Method}

\section{Design}

A repeated measures evaluation design was used to assess the Confident Kids Program. Quantitative data were collected through the completion of standardised questionnaires by the parents and teachers on two occasions: at the start of the 10-week group program, and at the completion of the group program.

\section{Participants}

Eleven Confident Kids programs involving 91 children were conducted in schools and agencies throughout urban and regional Victoria. Pre- and post-questionnaires were returned by 39 parents/carers and 48 teachers. As only 19 children had both parent and teacher pre- and post-questionnaires completed, the data from parents and teachers are reported separately.

The children were aged between 6 and 12 years of age $(M=9.0, S D=1.8)$. Sixty-three percent of the child participants were male. Parent respondents were all mothers (with the exception of 1 female foster carer). The age range of 
participating mothers was 28 to 58 years of age $(M=38.6, S D=6.0)$. Fifty-eight percent of the families had an average income of less than \$AUD40,000 per year. Demographic information on the school and community agencies involved was not collected.

\section{Procedure}

The ETP team conducted their regular one-day training workshops for professionals wanting to run the Confident Kids Program in their schools or community agencies. All trained leaders were offered free evaluation of any programs they conducted during the time period of this pilot.

Leaders recruited participants through distributing information to staff and families about the program and asking for referrals. The guidelines for group selection were that they comprised 6-10 children with a maximum 3 year age range, a balance of genders where possible, and some children with internalising behaviours as well as those with externalising behaviours. Leaders then conducted a face to face or phone interview with parents to discuss the program and gain permission for the child to attend. All parents whose children participated in the Confident Kids Program were invited to participate in the research. The program was implemented according to the structure outlined in the detailed program manual to ensure that treatment integrity was maintained.

To provide a comprehensive assessment of the Confident Kids Program, trained program group leaders distributed evaluation information to the families in their program one week prior to the program commencing. This included informed consent forms and also asked for signed consent to contact the child's teacher as part of the evaluation. Post-program questionnaires were distributed during the last week of the program. Parents and teachers could opt to use the reply paid envelope or to hand the questionnaires directly to the program group leaders to forward for evaluation. The incentive for leaders to support the evaluation was the promise of an individualised report on their group at the end of the program.

\section{Intervention}

In addition to the children attending the 10session program described above, there were also two meetings for parents/carers and two separate meetings for teachers. The aims of the two 90 minute parent meetings are to: inform parents about what their children will be learning in the program; invite parents to work in partnership with the school to assist their children; promote a consistent approach in the management of the child across the different systems in a child's life; and provide opportunity for two-way feedback between parents and group leaders. The aims of the teacher meetings paralleled those of the parent meetings.

\section{Measures}

Achenbach Child Behavior Checklist (CBCL) Parents' Report Form (Achenbach, 2001)

This measures children's emotional and behavioural difficulties. It is completed by parents/carers and takes 15-20 minutes for respondents with a fifth grade reading level. The form contains two sections which cover behaviour problems and competencies. The behavior problems section of the CBCL (Achenbach's 1991) version) contains a list of 118 behavioural problems. A 3-point scale is used to rate items ( $0=$ not true, $1=$ somewhat or sometimes true, 2 = very true or often true). The nine subscales are grouped into two 'broad-band' scales titled externalising (delinquent behavior and aggressive behavior) and internalising (withdrawn, somatic complaints, and anxiousdepressed) scales. High scores on the externalising and internalising scales are indicative of more severe behaviors. Clinical and borderline clinical cut-off points have been derived for each of these scales. The CBCL is well standardised and has adequate reliability and validity (see Achenbach, 1991).

Achenbach Child Behavior Checklist Teachers' Report Form (CBCL-TRF) (Achenbach, 2001)

The behaviour problems section of the TRF has the same scales as the parent form. A second section of the TRF measuring adaptive functioning is not reported in this paper. The CBCL-TRF is well standardised and has adequate reliability and validity (see Achenbach, 1991).

Kansas Parental Satisfaction Scale (KPS) (James, Schumm, Kennedy et al., 1985)

This brief (3-item) instrument is designed to measure parents' satisfaction with themselves as a parent, satisfaction with the behaviour of their children, and satisfaction with their relationship 
with their children. Parents respond on a 7-point scale ranging from 'extremely dissatisfied' to 'extremely satisfied'. The scale is easily completed in less than two minutes and is reported to be one of the few scales available to directly measure satisfaction with parenting. James et al. (1985) reported moderate to high intercorrelations between the items on the Kansas Parental Satisfaction Scale (.61 to .68) but found that they had significantly different means. The Kansas Parental Satisfaction scale is reported to have good concurrent validity, correlating significantly with the Kansas Marital Satisfaction Scale (James et al., 1985) and the Rosenberg Self-Esteem Scale (0.23 to 0.55$)$ in different studies (James et al., 1985).

\section{Parenting Scale (Arnold, O'Leary, Wolff \& Acker, 1993)}

Parenting practices were assessed using this 30item self-report scale which measures three dysfunctional discipline styles in parents of young children: Laxness (permissive discipline); Over-reactivity (authoritarian discipline physical punishment, threats, and power assertion); and Verbosity (lengthy verbal responses). Factor scores are calculated by summing the total scores divided by the number of items. Higher scores indicate dysfunctional parenting. Arnold et al. (1993) reported internal consistency alpha coefficients of Laxness $=.83$; Over-reactivity $=.82$ and Verbosity $=.63$. Testretest reliability was also acceptable $.83, .82$ \& .79 respectively, and scores on the three factors show positive correlations with objective measures of poor child behaviour and dysfunctional discipline by parents.

\section{Results}

\section{Child outcomes - parent reports}

Changes in mother reported problematic child behaviours were analysed using a MANOVA with internalising and externalising behaviour problem scores as the dependent measures (see Table 1). There were significant pre- to postprogram changes in children's internalising and externalising problems, $F(2,38)=15.2, p<$ .001 , partial eta squared $=.44$. Univariate tests found there were significant decreases in children's internalising behaviours and externalising behaviours.

Table 1. Change in Internalising and Externalising subscale scores on the Child Behaviour Checklist-Parents' Reports from pre- to post-program

\begin{tabular}{llllrcr}
\hline Behaviour problems subscales & $n$ & $\begin{array}{c}\text { Pre-program } \\
\text { Mean (SD) }\end{array}$ & $\begin{array}{c}\text { Post-program } \\
\text { Mean (SD) }\end{array}$ & $\boldsymbol{F}(\mathbf{1 , 3 9 )}$ & $\begin{array}{c}\boldsymbol{p} \\
\text { Partial eta } \\
\text { squared }\end{array}$ \\
\hline Internalising behaviour & 39 & $60.0(11.4)$ & $54.4(11.5)$ & 29.2 & $<.001$ & .44 \\
Externalising behaviour & 39 & $60.0(13.7)$ & $57.2(11.5)$ & 4.7 & $<.05$ & .13 \\
\hline
\end{tabular}

Table 2. Change in Behaviour Problems subscale scores on the Child Behaviour Checklist-Parents' Reports from pre- to post-program $(n=39)$

\begin{tabular}{|c|c|c|c|c|c|}
\hline Behaviour Problems subscales & $\begin{array}{c}\text { Pre-program } \\
\text { Mean T-score (SD) }\end{array}$ & $\begin{array}{c}\text { Post-program } \\
\text { Mean T-Score (SD) }\end{array}$ & $F(1,38)$ & $p$ & $\begin{array}{l}\text { Partial Eta } \\
\text { Squared }\end{array}$ \\
\hline Withdrawn & $58.2(9.5)$ & $55.4(7.4)$ & 13.1 & $<.001$ & .26 \\
\hline Somatic complaints & $57.9(8.2)$ & $54.9(6.7)$ & 8.7 & $<.001$ & .19 \\
\hline Anxious/depressed & $61.7(10.5)$ & $58.0(8.6)$ & 12.8 & $<.001$ & .25 \\
\hline Social problems & $62.7(10.4)$ & $61.1(11.3)$ & 2.4 & ns & .06 \\
\hline Thought problems & $60.2(9.4)$ & $57.6(8.4)$ & 6.6 & $<.05$ & .15 \\
\hline Attention problems & $61.5(10.3)$ & $59.1(10.0)$ & 4.9 & $<.05$ & .12 \\
\hline Delinquent behaviour & $60.6(10.4)$ & $59.1(10.2)$ & 2.4 & ns & .06 \\
\hline Aggressive behaviour & $62.7(12.4)$ & $58.9(8.6)$ & 10.7 & $<.001$ & .22 \\
\hline
\end{tabular}


A paired-sample t-test was performed to compare scores on the CBCL Total Behaviour subscale from pre- to post-program. According to parent report, there were significant changes in children's total behaviour problem scale scores from pre-program $(M=62.0, S D=12.7)$ to post-program $(M=57.4, S D=12.2), t(39)=$ $5.3, p<.001$. The eta squared statistic (.42) indicated a large effect size.

To determine which specific emotional and behavioral difficulties improved following participation in the program, eight subscales scores of the CBCL were compared pre- and post-intervention using a MANOVA (see Table 2). According to parent reports, there was a significant overall decrease in scores from preto post-intervention, $F(8,31)=3.45, p<.05$, partial eta squared $=.47$. Univariate tests found there were significant decreases in children's withdrawn behaviours, somatic complaints, anxious/depressed behaviours and aggressive behaviours $(p<.01)$. Improvements in the predicted direction in children's thought and attention problems were also reported $(p<.05)$.

As well as looking at statistical changes in children's internalising, externalising and total behaviour scores, clinical changes were also identified (see Table 3). Scores were categorised as falling into the normal, borderline clinical or clinical range at both pre- and post-program (see Achenbach 1991 for cut off scores).

Pre-program, more than half the children scored in the normal range on the Internalising scale and this increased at post-program. For the Externalising scale, only $40 \%$ of children scored in the normal range pre-program, and almost half (49\%) scored in the clinical range. Post-program just over half the children were now in the normal range with less than a quarter remaining in the clinical range. For the Total Behaviour
Table 3. Changes in clinical scores on the Child Behaviour Checklist-Parents' Reports from pre- to post-program

\begin{tabular}{|c|c|c|c|c|}
\hline$T$-score ranges & & $\begin{array}{l}\text { e-program } \\
\text { (\%) }\end{array}$ & $\begin{array}{c}\text { Pos } \\
n\end{array}$ & $\begin{array}{l}\text { t-program } \\
\text { (\%) }\end{array}$ \\
\hline \multicolumn{5}{|c|}{ Internalising scale } \\
\hline Normal & 21 & $(57 \%)$ & 25 & $(67 \%)$ \\
\hline Borderline & 4 & $(11 \%)$ & 1 & $(3 \%)$ \\
\hline Clinical & 12 & $(32 \%)$ & 11 & $(30 \%)$ \\
\hline \multicolumn{5}{|c|}{ Externalising scale } \\
\hline Normal & 15 & $(40 \%)$ & 19 & $(51 \%)$ \\
\hline Borderline & 4 & $(11 \%)$ & 10 & $(27 \%)$ \\
\hline Clinical & 18 & $(49 \%)$ & 8 & $(22 \%)$ \\
\hline \multicolumn{5}{|c|}{ Total behaviour problem scale } \\
\hline Normal & 14 & $(38 \%)$ & 21 & $(57 \%)$ \\
\hline Borderline & 2 & $(5 \%)$ & 3 & $(8 \%)$ \\
\hline Clinical & 21 & $(57 \%)$ & 13 & $(35 \%)$ \\
\hline
\end{tabular}

problems scale, only $38 \%$ of children were in the normal range pre-program, and this increased to $57 \%$ post-program.

\section{Child outcomes - teacher reports}

Pre- and post-program teacher questionnaires were completed on 48 children. Overall results showed that the Confident Kids Program had a positive impact in reducing children's internalising and externalising behaviours (measured on the CBCL-TRF). Changes in teacher reported problematic child behaviours were analysed using a MANOVA with internalising and externalising behaviour problem scores as the dependent measures (see Table 4).

According to teacher report, there were significant pre- to post-program changes in children's internalising and externalising problems, $F(2,46)=6.0, p<.01$, partial eta squared $=.21$. Univariate tests found there were significant decreases in children's internalising behaviours.

Table 4. Change in Internalising and Externalising subscale scores on the Child Behaviour Checklist-Teachers' Reports from pre- to post- program

\begin{tabular}{llllcr}
\hline Behaviour problems subscales & $n$ & $\begin{array}{c}\text { Pre-program } \\
\text { Mean (SD) }\end{array}$ & $\begin{array}{c}\text { Post-program } \\
\text { Mean (SD) }\end{array}$ & $\begin{array}{c}\text { Partial eta } \\
\text { squared }\end{array}$ \\
\hline Internalising behaviour & 48 & $61.6(10.6)$ & $58.1(10.6)$ & 7.5 & $<.05$ \\
Externalising behaviour & 48 & $63.1(10.3)$ & $62.5(10.7)$ & 0.5 & $\mathrm{~ns}$ \\
\hline
\end{tabular}


Table 5. Changes in clinical scores on the Child Behaviour Checklist-Teachers' Reports from pre- to post-program

\begin{tabular}{|c|c|c|c|c|}
\hline$T$-score ranges & $\begin{array}{r}\text { Pre-p } \\
n\end{array}$ & $\begin{array}{l}\text { rogram } \\
\text { (\%) }\end{array}$ & & $\begin{array}{l}\text { t-program } \\
\text { (\%) }\end{array}$ \\
\hline \multicolumn{5}{|c|}{ Internalising scale } \\
\hline Normal & 22 & $(47 \%)$ & 31 & $(66 \%)$ \\
\hline Borderline & 9 & $(19 \%)$ & 5 & $(11 \%)$ \\
\hline Clinical & 16 & $(34 \%)$ & 11 & $(23 \%)$ \\
\hline \multicolumn{5}{|c|}{ Externalising scale } \\
\hline Normal & 20 & $(42 \%)$ & 25 & $(53 \%)$ \\
\hline Borderline & 5 & $(11 \%)$ & 5 & $(11 \%)$ \\
\hline Clinical & 22 & $(47 \%)$ & 17 & $(36 \%)$ \\
\hline \multicolumn{5}{|c|}{ Total behaviour problem scale } \\
\hline Normal & 19 & $(40 \%)$ & 24 & $(51 \%)$ \\
\hline Borderline & 4 & (9\%) & 9 & $(19 \%)$ \\
\hline Clinical & 24 & $(51 \%)$ & 14 & $(30 \%)$ \\
\hline
\end{tabular}

A paired-sample t-test was performed to compare scores on the Total Behaviour subscale scores on the CBCL-TRF from pre- to postprogram. According to teacher report, there were no significant changes in children's total behaviour problem scale scores from preprogram $(M=64.2, S D=8.5)$ to post-program $(M=61.9, S D=10.4), t(48)=1.9, p<.06$.

Using teacher reports, scores on the CBCL were categorised as falling into the normal, borderline clinical or clinical range at both pre- and postprogram (see Achenbach 1991 for cut off scores). On the Internalising scale, less than half the children were in the normal range preprogram (47\%). By post-program this had increased to 66\%. For the Externalising scale, $47 \%$ of children were in the clinical range preprogram. This improved substantially postprogram with only $36 \%$ remaining in the clinical range and over half the children in the normal range. For the Total behaviour problems scale, just over half the children (51\%) scored in the clinical range at the beginning of the program. By post-program, only $30 \%$ remained in this clinical range. The numbers and proportions of children in each category are shown in Table 5.

\section{Parent outcomes}

The Confident Kids Program aimed to improve parenting satisfaction. Changes on the Kansas Parental Satisfaction Scale were analysed using ANOVA. There was a significant increase in mother reported parental satisfaction from preto post-program (Wilks' lambda $=.79, F(1,37)$ $=9.6, p<.001$ ) with an effect size of partial eta squared $=.21$.

The Confident Kids Program also aimed to reduce dysfunctional parenting styles. Results showed that the program had a positive impact in decreasing parents' dysfunctional parenting styles (measured on the Parenting Scale). Changes in parenting styles were analysed using a MANOVA with Laxness, Over-reactivity and Verbosity scores as the dependent measures. There was a significant decrease in scores across time (Wilks' lambda $=.72, F(3,24)=3.15, p<$ .04 ), with a large effect size (partial eta squared $=.28$ ). Table 6 presents the mean pre- and postprogram scores for mother-reported parenting styles and univariate findings.

\section{Discussion}

This study provided preliminary evidence that Confident Kids Program is an effective, shortterm program to improve children's emotional and behaviour problems at home and at school. Parental satisfaction increased and dysfunctional parenting practices were reduced. In particular, analysis of pre- and post-intervention parent data showed significant reductions in children's withdrawn behaviours, somatic complaints, anxious/depressed behaviours and aggressive behaviours. Teacher reports identified significant improvements in children's internalising behaviour. Non statistical examination of the

Table 6. Change in Parenting Scale Scores from pre- to post-program

\begin{tabular}{|c|c|c|c|c|c|c|}
\hline Parenting scales & $n$ & $\begin{array}{c}\text { Pre-program } \\
\text { Mean (SD) }\end{array}$ & $\begin{array}{c}\text { Post-program } \\
\text { Mean (SD) }\end{array}$ & $F(2,46)$ & $p$ & $\begin{array}{c}\text { Partial eta } \\
\text { squared }\end{array}$ \\
\hline Laxness & 27 & $3.1(0.87)$ & $2.8(0.79)$ & 4.4 & $<.05$ & .18 \\
\hline Over-reactivity & 27 & $3.3(0.69)$ & $3.0(0.68)$ & 3.8 & n.s. & .13 \\
\hline Verbosity & 27 & $4.0(0.68)$ & $3.0(0.85)$ & 4.3 & $<.05$ & .10 \\
\hline
\end{tabular}


clinical change scores also suggested that the program had moved some children's behaviour at school and at home into the normal range. The Confident Kids Program as a stand alone program appears to achieve effects comparable to the multi-component ETP (Hemphill \& Littlefield, 2001; Littlefield et al., 2000). These results are also consistent with data reported in previous studies that demonstrate children's social problem solving and emotion management training result in significantly reduced behavioural and emotional problems across time (Kazdin et al., 1987; Shure, 1993; Spivack \& Shure, 1989). Some reviews do not support the efficacy of training children in social skills and problem solving alone to reduce children's behavioural and emotional problems over the long term (Gresham, 1998; Taylor et al., 1999). Further studies are required to determine whether improvements in child behaviour and emotional problems are maintained in the longer term.

While the improvements in parents' satisfaction need to be interpreted with caution, they are significant and worthy of both discussion and further investigation. With the current research design, it is not possible to identify whether these positive changes for parents are the result of an improvement in their children's behaviour, the parent meetings attended, or a combination of both. Positive changes in a child's behaviour can help parents not only view their child more positively, but also reinforce the idea that behaviour is not necessarily stable - that with effective intervention it can be improved. Offering school based interventions can also provide parents with a positive experience of help seeking and may be the first step in them seeking further help in the future. It is possible that some parents invited to participate in multigroup programs may reject the invitation fearing that they are somehow to 'blame' for their child's difficulties. Having the option of offering an intervention with the dominant focus on the child can be a helpful way for schools to engage families in effectively addressing their child's needs. If these programs are offered as support, this can also improve the relationships between schools and families and have benefits for their continuing work together.

That the improvements in childrens' behaviour were more evident at home than at school is somewhat expected. When children learn new skills, they are more likely to exhibit them amongst a small number of people in their home before they are generalised to the larger arena of school. The competing demands on teachers from other children in a classroom setting may also mean that more subtle changes in children's behaviour are not as obvious as they are to parents. Longer term follow-up would help identify whether or not the participating children were able to generalise their skills to the school setting over time.

Several other advantages exist in being able to offer individual components of ETP. These include an increased likelihood of more children attending programs that do not require a weekly commitment from their parents and more programs being conducted due to the smaller number of leaders required.

The Confident Kids Program was of direct value to participating children and their families as participants have been equipped with skills to reduce emotional and behavioural difficulties. While the benefits to schools in terms of significant improvements in children's externalising behaviours are not so apparent, further research will help inform and possibly revise the program to strengthen the impact on externalising behaviours as well as the generalisation of improved behaviours to the school setting.

\section{Limitations and future directions}

The present evaluation of the Confident Kids Program did not use an experimental design, therefore the positive results must be considered as preliminary evidence supporting the efficacy of this program. This limitation may be addressed by further research that includes random assignment to a control and treatment group to provide a more rigorous test of the effectiveness of the program. Furthermore, follow-up data is required to ensure that improvements observed in the short term are maintained in the longer term. Another limitation of the study was the small sample size, meaning that the results must be interpreted with caution and are not necessarily generalisable to the broader population. The low return rate of questionnaires was mainly attributable to the programs being conducted by people who did not necessarily have a direct investment in the 
evaluation. While having the researchers themselves conducting the programs in schools can lead to an increase in return rates, the current model of using personnel already working in schools could be viewed as a greater reflection of reality and a better measure of program effectiveness. A further challenge identified by group leaders was that it was often difficult enough to get parents to agree to their children participating in the program. Many were concerned that if the parents were asked to complete questionnaires they may decide to withdraw their child from the program.

In conclusion, teaching children effective skills to reduce behavioural and emotional problems is proactive and preventative, with an aim of providing children with strategies to enhance their behavioral and emotional wellbeing and to enhance their relationships with peers and family members. While it is recognised that group programs offering a multi-systemic approach may be advocated in the literature as the preferred intervention to reduce childhood emotional and behavioral difficulties (WebsterStratton \& Reid, 2003), it is not always possible for parents and their children to access these interventions or for schools and community agencies to offer them. Providing more flexible options, particularly for programs suitable to be conducted in school settings, can only be of benefit to a larger number of children and their families. The Confident Kids Program offers an alternative evidence-based intervention to reduce childhood emotional and behavioural difficulties.

\section{Acknowledgement}

This research forms part of the ongoing evaluation of Exploring Together Programs and was conducted at the Parenting Research Centre, Melbourne, Australia.

\section{References}

Achenbach, T.M. (1991). Manual for the Child Behavior Checklist/4-18 and 1991 Profile. Burlington, VT: University of Vermont, Department of Psychiatry.

Achenbach, T.M. (2001). Child Behavior Checklist for Ages 6 to 18. Burlington, VT: University of Vermont, Department of Psychiatry.

American Psychiatric Association (1994). Diagnostic and Statistical Manual of Mental Disorders (DSM-IV) ( $4^{\text {th }}$ ed.). Washington, DC: APA.

Arnold, D.S., O’Leary, S.G., Wolff, L.S., \& Acker, M.M. (1993). The Parenting Scale: A measure of dysfunctional parenting in discipline situations. Psychological Assessment, 5, 137-144.

Brestan, E.V. \& Eyberg, S.M. (1998). Effective psychosocial treatments of conduct-disordered children and adolescents: 29 years, 82 studies, and 5,272 kids. Journal of Clinical Child Psychology, 27(2), 180-189.

Burke, S., Soltys, M., \& Trinder, M. (2008). A preliminary evaluation of the Together Parenting Program - a stand alone component of the Exploring Together Program. Australian e-Journal for the Advancement of Mental Health, 7(1), www.auseinet.com/journal/vol7iss1/burke.pdf

Council of Australian Governments (COAG). National Action Plan on Mental Health 2006 - 2011. http://www.coag.gov.au/meetings/140706/doc/nap_m ental_health.rtf (accessed Jan 2007).

DeAngelis, T. (2004). Taking action for children's mental health. Monitor on Psychology, 35(11), 38-41.

Eyeberg, S., Boggs, S.R., \& Algina, J. (1995). New developments in psychosocial, pharmacological, and combined treatments of conduct disorders in aggressive children. Psychopharmacology Bulletin, 31, 83-91.

Gresham, F.M. (1998). Social skills training: Should we raze, remodel, or rebuild? Behavioral Disorders, 24, 19-25.

Hemphill, S. (1996). Characteristics of conductdisordered children and their families: A review. Australian Psychologist, 31, 109-118.

Hemphill, S. \& Littlefield, L. (2001). Evaluation of a short-term group therapy program for children with behavior problems and their parents. Behavior Research and Therapy, 39, 823-841.

James, D., Shumm, W., Kennedy, C., Grigsby, C., Shectman, K., \& Nichols, C. (1985). Characteristics of the Kansas Parental Satisfaction Scale among two samples of married parents. Psychological Reports, 57, 163-169.

Kazdin, A.E. (1995). Conduct Disorders in Childhood and Adolescence ( $2^{\text {nd }}$ ed.). Newbury Park, CA: Sage.

Kazdin, A.E., Esveldt-Dawson, D.K., French, N.H., \& Unis, A.S. (1987). Effects of parent management training and problem-solving skills training combined in the treatment of antisocial child behaviour. Journal of the American Academy of Child and Adolescent Psychiatry, 26, 416-424.

Kazdin A.E. \& Weisz, J.R. (1998). Identifying and developing empirically supported child and adolescent treatments. Journal of Consulting and Clinical Psychology, 66, 19-36. 
Littlefield, L., Burke, S., Trinder, M., Woolcock, C., Story, K., Wilby, A., Falconer, B., \& Dunkley, T. (2000). Exploring Together Final Internal Evaluation Report. The Department of Health and Aged Care under its supporting families: National Parenting Initiative. Unpublished Report.

Maddern, L., Franey, J., McLaughlin, V., \& Cox, S. (2004). An evaluation of the impact of an interagency intervention programme to promote social skills in primary school children. Educational Psychology in Practice, 20(2), 135-155.

Neil, A.L. \& Christensen, H. (2007). Australian school-based prevention and early intervention programs for anxiety and depression: a systematic review. Medical Journal of Australia, 186(6), 305308.

Sanders, M.R., Ralph, A., Thompson, R., Sofronoff, K., Gardiner, P., Bidwell, K., \& Dwyer, S. (2007). Every Family: A Public Health Approach to Promoting Children's Well-being - Final Report. Brisbane: The University of Queensland.

Sawyer, M.G., Arney, F.M., Baghurst, P.A., Clark, J.J., Graetz, B.W., Kosky, R.J., Nurcombe, B., Patton, G.C., Prior, M.R., Raphael, B., Rey, J.M., Whaites, L.C., \& Zubrick, S.R. (2001). The mental health of young people in Australia: Key findings from the child and adolescent component of the national survey of mental health and well being. Australian and New Zealand Journal of Psychiatry, 35, 806-814.

Scott, S., Knapp, M., Henderson, J., \& Maughan, B. (2001). Financial costs of social exclusion: Follow up study of anti-social children into adulthood. British Medical Journal, 323, 191-194
Shure, M.B. (1993). I can problem solve (ICPS): Interpersonal cognitive problem solving for young children. Early Child Development and Care, 96, 4964.

Spivack, G. \& Shure, M.B. (1989). Interpersonal Cognitive Problem Solving (ICPS): A competencebuilding primary prevention program. Prevention in Human Services, 6, 151-178.

Taylor, T.K. \& Biglan, A. (1998). Behavioural family interventions for improving child-rearing: A review of the literature for clinicians and policy makers. Clinical Child and Family Psychology Review, 1(1), 41-60.

Taylor, T.K., Eddy, J.M., \& Biglan, A. (1999). Interpersonal skills training to reduce aggressive and delinquent behavior: Limited evidence and the need for an evidence-based system of care. Clinical Child and Family Psychology Review, 2, 169-182.

Webster-Stratton, C. \& Hammond, M. (1997). Treating children with early-onset conduct problems: A comparison of child and parent training interventions. Journal of Consulting and Clinical Psychology, 65, 93-109.

Webster-Stratton, C. \& Reid, M.J. (2003). Stress: a potential disruptor of parent perceptions and family interactions. Journal of Emotional and Behavioral Disorders, 11(3), 130-143.

Weist, M.D., Lever, N.A., \& Stephan, S.H. (2004). The future of school expanded mental health. The Journal of School Health, 74(6), 191.

Wren, F.J., Scholle, S.H., Heo, J., \& Comer, D.M. (2003). Pediatric mood and anxiety syndromes in primary care: who gets identified? International Journal of Psychiatry in Medicine, 33(1), 1-16. 